\title{
Knowledge, attitudes and practice of condom use among the married women in Mirpur area of Dhaka city, Bangladesh
}

\author{
Fatema Zohora Methe ${ }^{1}$, Shirin Sultana ${ }^{2}$, Faisal Muhammad ${ }^{2 *}$
}

\begin{abstract}
${ }^{1}$ Department of Public Health, Faculty of Arts and Social Sciences, American International University Bangladesh (AIUB), Dhaka, Bangladesh

${ }^{2}$ Department of Public Health, Faculty of Allied Health Sciences, Daffodil International University (DIU), Dhaka, Bangladesh
\end{abstract}

Received: 26 July 2018

Accepted: 28 August 2018

\section{*Correspondence:}

Dr. Faisal Muhammad,

E-mail: fokkanya@yahoo.com

Copyright: (c) the author(s), publisher and licensee Medip Academy. This is an open-access article distributed under the terms of the Creative Commons Attribution Non-Commercial License, which permits unrestricted non-commercial use, distribution, and reproduction in any medium, provided the original work is properly cited.

\begin{abstract}
Background: Condom is an important method of family planning and prevention of sexually transmitted infections. Condom is the only contraceptive method that can protect against both pregnancy and sexually transmitted infections. Unprotected sex leads to many unintended pregnancies and sexually transmitted infections (STIs). The family planning saves lives of women and children and improves the quality of life. This study was aimed to assess the knowledge, attitudes and practice of condom use among the married women in Mirpur area of Dhaka city in Bangladesh.

Methods: A descriptive cross-sectional study was conducted among the randomly selected sample of 101 women aged 15-49 years from selected areas of Mirpur in Dhaka city of Bangladesh. Pre-designed and pre-tested questionnaire was used to elicit the required information from the study participants using face to face interview. The collected data was analyzed using SPSS 21.0 version.

Results: Only 5.9\% of the study participants had ever used condom. Most of the study participants (93.1\%) considered a condom as an effective method for birth control and prevention of sexually transmitted infections (10.9\%). However, $36.6 \%$ of them believed that condom use had some harmful effects. The main reason for condom use among the users was for family planning $(83.3 \%)$ and the rest $(16.7 \%)$ mentioned that it was due to STIs prevention and family planning. The condom use was found significantly associated with age, educational level, partner's educational level, socio-economic status, and perceived risk of STIs.

Conclusions: The study revealed that the rate of condom use was very low among the study participants. This might be due to lack of knowledge about proper and effective use of condoms, low perception of risk of STIs, misperception about harmful effects of condoms and the use of other family planning methods by respondents.
\end{abstract}

Keywords: Attitude, Condom, Knowledge, Perception, Practices, Sexually transmitted infections

\section{INTRODUCTION}

Condom is an important method of family planning and prevention of sexually transmitted infections (STIs). Using condom is the only contraceptive method that can protect against both pregnancy and sexually transmitted infections (STIs). Family planning saves lives of women and children and it also improves the quality of life. ${ }^{1}$ The use of the condoms was traced back to several thousand years ago. Condoms were invented in the fifteenth century in response to syphilis epidemic in Europe. ${ }^{2}$ Unprotected sex causes many unintended pregnancies and sexually transmitted infections (STIs). Nevertheless, the condom use for dual protection is important and 
women need counseling on the correct and consistent use of condom. Condom is among the most popular forms of mechanical barriers as it gives protection for the genital tract from sexually transmitted infections (STIs). It also prevents pregnancy by acting as a barrier stopping semen from passing into the vagina. ${ }^{3}$

It was estimated that about 44 million couple use condom for family planning while as many as $60 \%$ of all condoms are used outside marriage. ${ }^{4}$ The effectiveness of condoms in preventing pregnancy or STIs depends on the user. Previous studies showed that pregnancy rate among correct condom users is about $2 \%$ per year. The risk of pregnancy or STI is greater when condoms are not used correctly and consistently with every sexual act. Nevertheless, when it's used every time and in the approved manner it could prevent up to about $95 \%$ of HIV transmission. ${ }^{5}$

Family planning save lives of women and children and improves quality of life. ${ }^{6}$ Men seem to play a vital role in the reproductive decisions; their actions can have unhealthy and even dangerous outcomes on family planning. ${ }^{7}$ There were many studies that reported the law rate of condom use across the world and it was due to lack of knowledge about proper and effective use of condoms.

In BDHS surveys, current use of contraception is defined as the proportion of currently married women who report that they are using a family planning method at the time of the survey. About $62 \%$ of currently married Bangladeshi women age 15-49 are currently using a contraceptive method, and 54\% use modern methods. The pill is by far the most widely used method (27\%), followed by injectable (12\%). About $8 \%$ of currently married women use a long-acting or permanent method such as female or male sterilization, implants, and IUDs. Traditional methods are used by $8 \%$ of women, of which the majority $(6 \%)$ use periodic abstinence and $6.4 \%$ use condoms. ${ }^{8}$ Condom uses rate of Bangladesh in rural area is 4.4 percent, and in urban area is 11.7 percent. ${ }^{8}$ A latest round of Bangladesh Behavioural Surveillance Survey (2006-07), reported that $13 \%$ and $28 \%$ of the brothel and hotel based FSWs used condom consistently with their regular clients respectively. ${ }^{9,10}$ Family planning is considered as one of the four pillars of safe motherhood program for reducing high maternal mortality in developing countries. There are at least four causal mechanisms through which family planning can directly reduce maternal deaths: reduce exposure to incidence of pregnancy, reduce vulnerability to abortion risks, postpone pregnancies during prematurity of pelvis development by delaying the first birth, and reduce the hazards of frailty from high parity pregnancies. Condom is shown to reduce most infectious diseases and other gynecological morbidities. This study was aimed to assess the knowledge, attitudes and practice of condom use among the married women in Mirpur area of Dhaka city in Bangladesh.

\section{METHODS}

A descriptive type of cross-sectional study was conducted in selected area of Mirpur in Dhaka city. The study was conducted for a period of 6 months (April to October 2017) and the study populations were all the married women in the selected area of Mirpur in Dhaka City.

A total of 101 married women residing in selected area of Mirpur during the study period were selected using simple random sampling technique (probability sampling) which was applied to determine the sample size. The study participants aged between $15-49$ years old were included and the respondents who were sick or not available at the time of data collection were excluded. A pre-tested semi-structured questionnaire was used in the present study and the data was collected by face to face interview. The raw data was checked twice and coded in the same day of data collection with the view to simplifying the data- entry. Data were entered into statistical package for social sciences (SPSS) 21.0 version for analysis.

\section{Ethical considerations}

Formal approval was obtained from Research Review Committee of American International UniversityBangladesh (AIUB). A verbal informed consent was taken from the study participant before interview and objectives of the research were clarified to them. Respondents were compelled to answer the question, they could leave independently on their wish, and questions were asked in a simple way that's in the local language. Confidentiality and privacy of the information provided by the participants were maintained.

\section{RESULTS}

\section{Socio-demographic characteristics of the respondents}

Table 1 showed that among the study participants the highest percentage $(58.4 \%)$ were in the age group 24 years and below, followed by 25-31 years (31.7\%). Most of the study participants $(83.0 \%)$ were Muslims and the rest of them were non-Muslims $(17.0 \%)$. Close to sixtenths $(59.0 \%)$ of the study participants were from nuclear family and the rest were from joint family. The majority $(48.5 \%)$ of the study participants had 0-1 living children, followed by 2-3 living children (37.6\%).

Among the study participants the majority of them were illiterate $(29.7 \%$ ) and about $29.7 \%$ had Secondary level of education, followed by primary level of education $(25.7 \%)$ and the rest had pre-university education. Most of the respondent's partners had primary level of education $(31.7 \%)$ and about $28.7 \%$ were illiterate. About $28.7 \%$ of the respondent's partners had secondary level of education and the rest had pre-university course $(10.9 \%)$. Among the respondent the highest percentage of 
the respondent were housewife $(59.4 \%)$ and the rest were employed $(40.6 \%)$.

Table 1: Socio-demographic characteristics of the respondents $(n=101)$.

\begin{tabular}{|c|c|c|}
\hline Variables & Frequency & Percentage \\
\hline \multicolumn{3}{|l|}{ Age (years) } \\
\hline$\leq 24$ & 59 & 58.4 \\
\hline $25-31$ & 32 & 31.7 \\
\hline $32-38$ & 7 & 6.9 \\
\hline $39-49$ & 2 & 3.0 \\
\hline Mean \pm SD & \multicolumn{2}{|l|}{$22.01 \pm 9.32$} \\
\hline \multicolumn{3}{|l|}{ Religion } \\
\hline Muslim & 83 & 82.2 \\
\hline Non-Muslim & 18 & 17.8 \\
\hline \multicolumn{3}{|l|}{ Family type } \\
\hline Nuclear & 41 & 40.6 \\
\hline Joint & 60 & 59.4 \\
\hline \multicolumn{3}{|l|}{ Number of children } \\
\hline $0-1$ & 49 & 48.5 \\
\hline $2-3$ & 38 & 37.6 \\
\hline$\geq 4$ & 14 & 13.9 \\
\hline \multicolumn{3}{|c|}{ Educational Status of the respondents } \\
\hline Illiterate & 30 & 29.7 \\
\hline Primary & 26 & 25.7 \\
\hline Seondary & 30 & 29.7 \\
\hline Pre-University Course & 15 & 14.9 \\
\hline \multicolumn{3}{|c|}{ Educational status of the respondent's partner } \\
\hline Illiterate & 29 & 28.7 \\
\hline Primary & 32 & 31.7 \\
\hline Seondary & 29 & 28.7 \\
\hline Pre-University Course & 11 & 10.9 \\
\hline \multicolumn{3}{|c|}{ Occupation of respondents } \\
\hline House wife & 60 & 59.4 \\
\hline Employed & 41 & 40.6 \\
\hline
\end{tabular}

\section{Knowledge and Attitudes towards condom use}

Table 2 shows that more than nine-tenths $(93.1 \%)$ of the study participants stated that the condoms are used for birth control and about $24.8 \%$ of the respondents had knowledge about proper condom use.

Table 2: Knowledge and attitudes towards condom use $(n=101)$.

\begin{tabular}{|ll|l}
\hline $\begin{array}{l}\text { Items } \\
\begin{array}{l}\text { Condom are used for birth } \\
\text { control }\end{array}\end{array}$ & $94(93.1)$ & $7(6.9)$ \\
\hline $\begin{array}{l}\text { Knowledge about proper } \\
\text { condom use }\end{array}$ & $25(24.8)$ & $76(75.2)$ \\
\hline $\begin{array}{l}\text { Condom prevent STIs } \\
\begin{array}{l}\text { Condom use has some side } \\
\text { effects }\end{array}\end{array}$ & $11(10.9)$ & $90(89.1)$ \\
\hline Feels shy to purchase condom & $55(54.5)$ & $46(45.5)$ \\
\hline
\end{tabular}

Only about $10.9 \%$ of the study participants considered STIs transmission can be reduced through condom use and about $36.6 \%$ of the study participants mentioned that condom use has some side effects. More than half $(54.5 \%)$ of the study participants feels shy to purchase condom.

\section{Distribution of the respondents by condom practicing}

Table 3 showed that the rate of condom use among the study participants was $5.9 \%$, while about $94.1 \%$ never used condoms in their life.

Table 3: Distribution of the respondents by condom practicing $(\mathbf{n}=\mathbf{1 0 1})$.

\begin{tabular}{|c|c|c|}
\hline Item & Frequency & Percentage \\
\hline \multicolumn{3}{|l|}{ Condom practicing } \\
\hline Condom user & 6 & 5.9 \\
\hline Non-condom user & 95 & 94.1 \\
\hline \multicolumn{3}{|l|}{ Reason for condom use } \\
\hline $\begin{array}{l}\text { Birth control/family } \\
\text { planning }\end{array}$ & 5 & 83.3 \\
\hline STIs Prevention & 0 & 0.0 \\
\hline Both & 1 & 16.7 \\
\hline \multicolumn{3}{|c|}{ Reason for non-condom use } \\
\hline Refuse condom use & 17 & 17.9 \\
\hline Desire for conception & 14 & 14.7 \\
\hline $\begin{array}{l}\text { Use of other method by } \\
\text { female }\end{array}$ & 20 & 21.1 \\
\hline Use of coitus interrupts & 2 & 2.1 \\
\hline Rejection by partner & 15 & 15.8 \\
\hline $\begin{array}{l}\text { Decreased sexual } \\
\text { pleasure }\end{array}$ & 24 & 25.2 \\
\hline Religious reason & 3 & 3.2 \\
\hline
\end{tabular}

The main reason for condom use among the condom users was for family planning $(83.3 \%)$.

The reasons for non-condom use among the respondents, includes: decrease in sexual pleasure $(25.2 \%)$, use of other method $(21.1 \%)$, refuse condom use (17.9\%), rejection by partner $(15.8 \%)$, desire for conception $(14.7 \%)$, religious reason $(3.2 \%)$ and the rest mentioned use of coitus interrupts.

\section{Associations between condom use and socio- demographic characteristics}

Table 4 shows that among condom users (5.9\%) of different age groups, the highest level of condom use was among the study participants of age group of 25-31 years, which was significantly higher than other age group.

It was also found that the age of the study participants was statistically significant $(\mathrm{P}=0.048)$ with condom use. It also reported that the lowest percentage of condom use was among the illiterate study participants, while the highest percentage of condom use was among the study participants with secondary and pre-university course $(\mathrm{P}<0.003)$. At the same time there was statistically 
significant association between condom use and educational state of the partner $(\mathrm{P}=0.010)$. The highest level of condom use was among higher socioeconomic status study participants with statistically significant association $(\mathrm{P}=0.031)$ of previous variable with condom use.

Table 4: Associations between Socio-demographic Variables and Condom Use $(n=101)$.

\begin{tabular}{|c|c|c|c|c|c|}
\hline \multirow{2}{*}{ Variables } & \multicolumn{2}{|c|}{ Condom } & \multirow[b]{2}{*}{ Total } & \multirow[b]{2}{*}{$\chi^{2}$} & \multirow{2}{*}{$\begin{array}{l}\text { P- } \\
\text { value }\end{array}$} \\
\hline & User & $\begin{array}{l}\text { Non- } \\
\text { user }\end{array}$ & & & \\
\hline \multicolumn{6}{|l|}{ Age group } \\
\hline$\leq 24$ & 1 & 58 & 59 & & \\
\hline $25-31$ & 5 & 27 & 32 & 0.906 & 0.048 \\
\hline $32-38$ & 0 & 7 & 7 & & \\
\hline $39-49$ & 0 & 3 & 3 & & \\
\hline \multicolumn{6}{|c|}{ Educational level of respondents } \\
\hline Illiterate & 0 & 30 & 30 & & \\
\hline Primary & 1 & 25 & 26 & 3.996 & 0.003 \\
\hline Secondary & 1 & 29 & 30 & & \\
\hline $\begin{array}{l}\text { Pre- } \\
\text { university } \\
\text { course }\end{array}$ & 4 & 11 & 15 & & \\
\hline \multicolumn{6}{|c|}{ Partner educational level } \\
\hline Illiterate & 0 & 29 & 29 & & \\
\hline Primary & 1 & 31 & 32 & 1.291 & 0.010 \\
\hline Secondary & 2 & 27 & 29 & & \\
\hline $\begin{array}{l}\text { Pre- } \\
\text { university } \\
\text { course }\end{array}$ & 3 & 8 & 11 & & \\
\hline \multicolumn{6}{|c|}{ Socio-economic status } \\
\hline Low & 1 & 63 & 64 & & \\
\hline Medium & 2 & 18 & 20 & 0.955 & 0.031 \\
\hline High & 3 & 14 & 17 & & \\
\hline \multicolumn{6}{|c|}{ Respondents occupation } \\
\hline Housewife & 3 & 57 & 60 & & \\
\hline Employed & 3 & 38 & 41 & 0.234 & 0.629 \\
\hline \multicolumn{6}{|c|}{ Number of living child } \\
\hline $0-1$ & 4 & 45 & 49 & & \\
\hline $2-3$ & 2 & 36 & 38 & 0.349 & 0.510 \\
\hline$\geq 4$ & 0 & 14 & 14 & & \\
\hline \multicolumn{6}{|c|}{ Perceived risk of STIs } \\
\hline Yes & 3 & 8 & 11 & & \\
\hline No & 3 & 87 & 90 & 0.053 & 0.002 \\
\hline Total & 6 & 95 & 101 & & \\
\hline
\end{tabular}

There was no statistically significant association $(\mathrm{P}=0.629)$ between respondent occupation, number of living child $(\mathrm{P}=0.510)$ and condom use.

The highest level of condom use was found among the study participants who perceived risk of STIs while the lowest level of condom use was among the study participants who did not perceive risk of STIs.

However, the perceiving risk of STIs was found to be significantly associated with the condom use $(\mathrm{P}=0.002)$.

\section{DISCUSSION}

It is essential to study the pattern of condom use which is now not only important for family planning and reducing fertility indices but also a life saver by preventing HIV infection. When properly used, male condoms represent a proven and effective means for family planning and preventing transmission of HIV/AIDS and other STIs. ${ }^{11}$ Men play a powerful and even dominant role in the reproductive decisions sometimes regardless of their partner wishes or health.

Therefore, it is important to direct the focus of health programs to advocate for a healthy male sexual behavior. $^{12}$

Among all respondents, condoms were considered as an effective method of contraception and prevention of transmission of sexually transmitted infections by $93.1 \%$ and $10.9 \%$ respectively.

The finding of this study reported that the knowledge and attitude of condom use was very low. A similar study was conducted in Rajshahi district of Bangladesh which showed that knowledge and use of contraception were low. Condoms were only used in $17 \%$ of the cases. ${ }^{13}$

The present study showed that the rate of condom use among the study participants was only $5.9 \%$, while $94.1 \%$ never used condoms in their life. The main reason for condom use among the condom users was for family planning $5.0 \%$ and $0.9 \%$ used condom for both of family planning and prevention of STIs.

This finding is similar to that of a study conducted in Iraq which reported that Condoms were considered by respondents as an effective method of contraception and prevention of sexually transmitted infections $33.2 \%$ and $28.3 \%$ respectively. ${ }^{1}$

There was a significant association between condom use and respondents age group by having a higher rate of use among 25-31 years age group. This result was consistent with that of a study conducted in Turkey. ${ }^{14}$ This may be due to fact that younger age groups are more sexually active and by using condoms they could avoid unwanted pregnancy and eliminate STD transmission.

There was significant association between both of educational and marital state of respondent with condom use; this result is in line with the findings of the studies conducted in Nigeria and Mexico City. ${ }^{15,16}$ There was higher level of condom use $17.6 \%$ among higher socioeconomic status, this result was consistent with a study conducted in Pakistan. ${ }^{17}$

The result may be due to a better accessibility to family planning services and an easier access to information about awareness and prevention from STIs by people from higher socio-economic class. The present study 
found a statistically significant difference among Knowledge Attitude and Practice of condom use with age, educational level of respondents, educational level of the partner, perceived risk of STIs and socio-economic class whereas there was no any relationship among KAP of condom use with type of family, occupation, and number of living children.

Another study found a statistically significant association among condom use with age, socio-economic status, respondent and wife educational level. ${ }^{18}$

\section{CONCLUSION}

The findings reported that the rate of condom use was very low among the study participants. The study participant's level of knowledge about proper and effective use of condom for family planning and protection from STIs were also very low. The study participant's level of awareness about STIs was low in addition to misperceptions about harmful effects of condom. The association was found to be existing between age, educational level of the respondents, partner's level of education, perceived risk of STIs and socio-economic status with condom use. KAP of the study participants significantly outlines the steps needed to improve their knowledge and rate of condom use through periodic health education programs.

\section{Recommendations}

Continuous health education campaigns should be organized on sexuality, proper usage and advantages of condoms aiming at changing the negative attitude. This can be done through IEC (Information Education and Communication)/BCC (Behavior Change Communication) materials.

Funding: No funding sources Conflict of interest: None declared

Ethical approval: The study was approved by the Institutional Ethics Committee

\section{REFERENCES}

1. Aziz SI, Jwan MS. Knowledge, Attitudes and Practice of Condom Use among Males Aged (15-49) Years in Erbil Governorate Glob J Health Sci. 2012; 4(4):27-36.

2. Lewis M.A. In: Brief history of condoms. Mindel A. Condoms., London: BMJ;2000;1-16.

3. Jain AP, Behere P, Jain P, Jain M, Joshi R, Jain S, et al. Textbook of Family Medicine. Hyderabad, New Delhi: Pars medical publisher; 2009.

4. Gardner R, Blackburn RD, Upadhyay UD, Closing the condom gap: Baltimore, Johns Hopkins school of Public Health population information Program. Popul Rep H. 1999;1(9):1-6.
5. USAIDS and WHO. Family planning a global handbook for providers. 2007; 202-10. Available from: www.who.int./reproductivehealth/public

6. World Health Organization. Health benefits of family planning. $1995 . \quad$ Available from: whqlibdoc.who.int/hq/1995/WHO_FHE_F P)P.

7. Dernnan M. Reproductive Health: new perspectives on mens participation. Baltimore, Johns Hopkins school of Public Health population information Program. Poul Rep J.1998;46:1-6.

8. National Institute of Population Research and Training (NIPORT), Mitra and Associates, and ICF International. 2015. Bangladesh Demographic and Health Survey: Key Indicators. Dhaka, Bangladesh, and Rockville, Maryland, USA: NIPORT, Mitra and Associates, and ICF International, 2014.

9. Cornish F. Making 'Context' concrete: a dialogical approach to the society-health relation. J Health Psychol. 2004; 9(2):281-94.

10. Jenkins C. Female sex worker HIV prevention projects: Lessons learnt from Papua New Guinea, India and Bangladesh. UNAIDS; Geneva, Switzerland: 2000.

11. UNAIDS: The male condom: technical update. Geneva, UNAIDS, 2000 (A Best practical collection) 2000. Available from: http://data.unaids.org|publications|IRCpub01|JC302TU1 8MaleCondom_en.pdf

12. Lasse A, Becker S. Husband-wife communication about family planning and contraceptive use in Kenya. Int Fam Plan Perspect. 1997;23(1):15-20.

13. Moisur R, Rafiqual I, Matin A. Male contraceptive behavior in Rajshahi district of Bangladesh. Med Sci Monit. 2009; 7(2):15-19.

14. Ozvaris SB, Dogan BG, Akin A. Male involvement in family planning in Turkey. In World Health Forum 1998;19(1):76-8.

15. Chingle MP, Odunze PA, Mohammed A, Bitto TT, Sodipo OY, Zoakah AI. Predictors of male condom utilization in Plateau State, Nigeria. Niger J Clin Pract. 2017;20:1079-87.

16. Hernandez-Giron CA, Cruz-V Aldez A, QuiterioTrendo M, Uribe-Salas F, Peruga A, Hernandez-Avila M. Factors associated with condom use in the male population of Mexico City. Int J STD AIDS. 1999;10(2):112-7.

17. Mustafa G, Azmat SK, Hameed W, Ali S, Ishaque M, Hussain W, et al. Family planning knowledge, attitudes, and practices among married men and women in rural areas of Pakistan: Findings from a qualitative need assessment study. Int J Reprod Med. 2015;2015.

18. Ismael AS, Zangana JMS. Knowledge, attitude and practice of condom use among males aged (15-49) years in Erbil Governorate. Global J Health Sci, 2012; 4(4):27-36.

Cite this article as: Methe FZ, Sultana S, Muhammad F. Knowledge, attitudes and practice of condom use among the married women in Mirpur area of Dhaka city, Bangladesh. Int J Reprod Contracept Obstet Gynecol 2018;7:3919-23. 